\title{
A Cross Cultural Study on Aggression in a Group of College Students from West Bengal and Jammu \& Kashmir
}

\author{
Bilal Ahmad Lone ${ }^{1 *}$, Sadhan Dasgupta ${ }^{2}$
}

\section{ABSTRACT}

The present study was to examine a cross cultural study on aggression in a group of college students from west Bengal and Jammu \& Kashmir. Cluster sampling procedure was taken for the selection of sample total 491 college students (both male \& female) in the study. The ex-post facto correlation design was used and results showed that there is relationship between experience \& expression of aggression and each of the variables, namely, personality, frustration, parental bonding and perceived life stress.

Keywords: Aggression, Frustration, Gender Differences, Antisocial Behaviour, Culture

Culture is defined by shared knowledge and meaning that is derived through processes of interaction and communication (Ramirez, J.M., 1993).Recently, cross cultural researches in psychology have focused on discovering what biological, environmental, psychological and social factors influence aggressive behaviour and on how to use these discoveries to reduce unwarranted aggression. The factors can be categorised as features of the situation or as features of the person in the situation. Andreu et al. (1998), Culture is an important factor that plays a role in the experience and expression of aggression. Anthropological research has found that some cultures are relatively low on aggression. Empirical cross cultural research has found differences in the level of aggression between cultures. It also found that American men resorted to physical aggression more readily than Japanese or Spanish men, whereas Japanese men preferred direct verbal conflict more than their American and Spanish counterparts.

Furthermore, most studies are still based on Western bases and perpetuate ethnocentric cultural imperialism. Research in social psychology should be decentred to non-Western constructs, include both group level and individual level variables and conducted by multicultural research teams. In addition to these methodological and empirical points of criticism, cross cultural

\footnotetext{
${ }^{1}$ Ph.D. Scholar, Dept. of Applied Psychology, University of Calcutta

${ }^{2}$ Professor, Dept. of Applied Psychology, University of Calcutta

*Responding Author

(C) 2016 I B Lone, S Dasgupta; licensee IJIP. This is an Open Access Research distributed under the terms of the Creative Commons Attribution License (http://creativecommons.org/licenses/by/2.0), which permits unrestricted use, distribution, and reproduction in any Medium, provided the original work is properly cited.
} 


\section{A Cross Cultural Study on Aggression in a Group of College Students from West Bengal and Jammu \& Kashmir}

psychology needs to emphasise new theoretical frameworks (such as dynamic constructive view), put them to an empirical test and focus on social interrelations and individual differences.

Aggression is a behaviour aimed at causing physical or psychological pain to any living being. It may be of direct or indirect type. Direct aggression again may be physical or verbal. Physical aggression includes hitting, punching, pushing, slapping and kicking etc. On the other hand, verbal aggression means abuse, spreading of rumours, malign etc. Any aggressive behaviour that is carried out via another person is considered as indirect aggression. Many theories regarding aggression have been postulated. According to some scientists this behaviour is largely related to learning from social environment. Another hypothesis suggests association of this behaviour with frustration which may occur after being prevented for reaching goal.

Socio-cultural factors such as changes in family roles, divorce, child abuse, unemployed parents and community racial tension are often regarded as contributing factors to personal violence in the colleges. In addition, urban society tends to be violent and some aspects of this violence overflow into the schools (Nuttal and Kalesnik 1987). Poverty may be another important factor in aggression. Poverty decreases the essential resources necessary for social development and increases the stressors that impede effective parenting and problem solving (Nuttal and Kalesnik 1987).

The strongest Big 5 predictor of aggressive behaviour is agreeableness, which is characterised as good-natured, trustful and cooperative (John \& Srivastava, 1999). It is negatively related to selfreport and peer-report aggressive behaviour and violence. Conscientiousness is characterised by being responsible, orderly and dependable (John \& Srivastava, 1999) and tends to negatively related to aggression (Sharpe \& Desai, 2001). A more recent study (Costa, Terracciano \& McCrae, 2001) produced quite a different pattern of results. Although women reported themselves as being higher in neuroticism, agreeableness, warmth and openness to feelings, the research need to focus magnitude of gender differences varied across cultures. There were also little variations across cultures in sex-role ideology (there was however, quite a large variation within cultures- something the author did not consider).

The main characteristics of psychological stress are that it is a product of individual's perception of the situation. This approach is consistent with lazarus's $(1966,1976)$ concept of cognitive of appraisal. According to Lazarus "stress is not out there in the environment, though it may originate there. Stress depends on not only the external condition, but also on internal condition, the way the person or animal is constructed psychologically. Larazus believed factors emerging from environmental condition (e.g., feeling of competence, hopeless and so on) determine the extent to which an individual perceives a situation as psychologically threatening or harmful. 


\section{A Cross Cultural Study on Aggression in a Group of College Students from West Bengal and Jammu \& Kashmir}

Family is the most important part of the child's environment (Adams, 1966). Parental bonding encompasses both parental care and parental protection, the experiences that individual has in early life at home with his family in general and his parents in particular are major determinants of a person's adjustment process during adolescence and in later life (Paker et al.,). Children of physically punitive parents tend to use similar aggression when relating to others. Their parents are often disciplined them by screaming, slapping, and breathing, thus modelling aggression as a method of dealing with problems (Patterson et al.,)

In conclusion, it may be said that aggression is a serious problem in individual, social, national and international spheres. The present study was conducted to explore aggressive behaviour in cultural factors in the context of West Bengal and Jammu \& Kashmir. Aggression as biological, social and environmental phenomenon has detained the attention of social psychologists and as such the present investigation reflects on some important aspects of aggression in relation to gender, cultural group and residential background. The computation of data has provided some important findings on gender, cultural group and residential background responsible for induction of aggression.

\section{OBJECTIVES}

- To assess whether five different dimensions of personality (neuroticism, extroversion, openness, agreeableness and conscientiousness)are related to experience and expression of aggression, when it is considered in terms of two groups of students coming from two cultural set-up, i.e., from West Bengal and Jammu \& Kashmir.

- $\quad$ To assess whether there is any relationship between perceived life stress and experience and expression of aggression, when it is considered in terms of two groups of students coming from two cultural set-up, i.e., from West Bengal and Jammu \& Kashmir.

- $\quad$ To assess whether there is any relationship between frustration and experience and expression of aggression, when it is considered in terms of two groups of students coming from two cultural set-up, i.e., from West Bengal and Jammu \& Kashmir.

- $\quad$ To assess whether there is any relationship between parental relationship and experience and expression of aggression, when it is considered in terms of two groups of students coming from two cultural set-up, i.e., from West Bengal and Jammu \& Kashmir.

\section{Variable of the study:}

- $\quad$ This is an ex-post facto correlational study where the nature and extent of relationship between the following variables with aggression have been studied in a group of college students from west Bengal and Jammu \& Kashmir.

- Independent variable- Different dimensions of personality, perceived life stress, level of frustration, parental bonding.

- $\quad$ Dependent variable - Experience \& expression of aggression. 


\section{Tools to be used:}

- $\quad$ State trait anger expression inventory (C.D. Spielber et al, 1983).

- $\quad$ Neo-five factor inventory (Costa \& McCrac, 1992).

- $\quad$ Parental Bonding instrument (Parker et al, 1979).

- $\quad$ Reaction to frustration Scale (B. M. Dixit, D. N. Srivastava, 2010).

- $\quad$ Perceived life stress Scale (Singh et al, 1983).

\section{Sample:}

The sample comprised of 245 college students (both male and female) in Kolkata, West Bengal, (age ranging $20-25$ years) were selected through cluster sampling for testing the hypothesis. Similarly, the sample comprised of 246 college students (both male and female) in Kashmir, Jammu \& Kashmir, (age ranging 20-25 years) were selected through cluster sampling for testing the hypothesis. Thus a cluster sampling procedure was taken for the selection of the subjects in the study.

Table: 1 Shows correlation between different dimensions of personality (neuroticism, extroversion, openness, agreeableness and conscientiousness) and different dimensions of aggression (experience and expression) of college students from West Bengal and Jammu \& Kashmir.

\begin{tabular}{|l|l|l|l|l|l|l|}
\hline & S-ANG & T-ANG & A-IN & A-OUT & A-CONT & A- EXP \\
\hline $\begin{array}{l}\text { N Of West } \\
\text { Bengal }\end{array}$ & 0.098 & $0.189^{* *}$ & 0.121 & $0.144^{*}$ & -0.098 & $0.171^{* *}$ \\
\hline $\begin{array}{l}\text { N Of Jammu } \\
\text { \& Kashmir }\end{array}$ & -0.022 & -0.088 & -0.095 & -0.039 & -0.111 & 0.067 \\
\hline $\begin{array}{l}\text { E Of West } \\
\text { Bengal }\end{array}$ & -0.011 & 0.067 & -0.002 & 0.039 & -0.060 & 0.072 \\
\hline $\begin{array}{l}\text { E Of Jammu } \\
\text { \& Kashmir }\end{array}$ & -0.013 & -0.012 & -0.001 & 0.026 & $-0.202^{* *}$ & $0.146^{*}$ \\
\hline $\begin{array}{l}\text { O Of West } \\
\text { Bengal }\end{array}$ & 0.001 & 0.043 & 0.110 & 0.036 & -0.084 & $-0.155^{*}$ \\
\hline $\begin{array}{l}\text { O Of Jammu } \\
\text { \& Kashmir }\end{array}$ & -0.041 & -0.108 & $0.210^{* *}$ & -0.053 & $-0.266^{* *}$ & $0.257^{* *}$ \\
\hline $\begin{array}{l}\text { A Of West } \\
\text { Bengal }\end{array}$ & -0.047 & 0.050 & 0.075 & 0.005 & -0.069 & 0.104 \\
\hline $\begin{array}{l}\text { A Of Jammu } \\
\text { \& Kashmir }\end{array}$ & -0.035 & 0.011 & 0.003 & -0.104 & $-0.247^{* *}$ & 0.117 \\
\hline $\begin{array}{l}\text { C Of West } \\
\text { Bengal }\end{array}$ & -0.072 & 0.077 & $0.156^{*}$ & -0.041 & -0.041 & $0.145^{*}$ \\
\hline $\begin{array}{l}\text { C Of Jammu } \\
\text { \& Kashmir }\end{array}$ & $0.189 * *$ & 0.014 & $-0.177^{* *}$ & $-0168 * *$ & $0.155^{*}$ & 0.077 \\
\hline
\end{tabular}


A Cross Cultural Study on Aggression in a Group of College Students from West Bengal and Jammu \& Kashmir

Table: 2 Shows correlation between stress and different dimensions of aggression (experience and expression) of college students from West Bengal and Jammu \& Kashmir.

\begin{tabular}{|l|l|l|l|l|l|l|}
\hline & S-ANG & T-ANG & A-IN & A-OUT & A-CONT & A- EXP \\
\hline $\begin{array}{l}\text { Stress Of } \\
\text { West } \\
\text { Bengal }\end{array}$ & $0.198^{* *}$ & -0.063 & 0.029 & 0.095 & $0.133^{*}$ & -0.017 \\
\hline $\begin{array}{l}\text { Stress Of } \\
\text { Jammu } \\
\text { \& Kashmir }\end{array}$ & $0.142^{*}$ & -0.113 & $-0.245^{* *}$ & $0.175^{* *}$ & $0.217^{* *}$ & $-0.170^{* *}$ \\
\hline
\end{tabular}

Table: 3 Shows correlation between different dimensions of frustration and different dimensions of aggression (experience and expression) of college students from West Bengal and Jammu \& Kashmir.

\begin{tabular}{|l|l|l|l|l|l|l|}
\hline & S-ANG & T-ANG & A-IN & A-OUT & A-CONT & A- EXP \\
\hline $\begin{array}{l}\text { A Of West } \\
\text { Bengal }\end{array}$ & $-0.143^{*}$ & $0.147^{*}$ & $0.139^{*}$ & $0.133^{*}$ & 0.021 & 0.106 \\
\hline $\begin{array}{l}\text { A Of } \\
\text { Jammu } \\
\text { \& Kashmir }\end{array}$ & $-0.156^{*}$ & -0.034 & $0.382^{* *}$ & $-0.420^{* *}$ & $-0.355^{* *}$ & $0.187^{* *}$ \\
\hline $\begin{array}{l}\text { R Of West } \\
\text { Bengal }\end{array}$ & 0.011 & 0.067 & 0.045 & $-0.127^{*}$ & -0.014 & -0.071 \\
\hline $\begin{array}{l}\text { R Of } \\
\text { Jammu } \\
\text { \& Kashmir }\end{array}$ & $-0.131^{*}$ & 0.039 & $-0.159^{* *}$ & $-0.343^{* *}$ & $-0.317^{* *}$ & $0.202^{* *}$ \\
\hline $\begin{array}{l}\text { F Of West } \\
\text { Bengal }\end{array}$ & 0.038 & -0.071 & 0.037 & 0.124 & 0.119 & -0.092 \\
\hline $\begin{array}{l}\text { F Of } \\
\text { Jammu } \\
\text { \& Kashmir }\end{array}$ & $-0.175^{* *}$ & 0.042 & $0.388^{* *}$ & $-0.416^{* *}$ & $-0.365^{* *}$ & $0.193^{* *}$ \\
\hline $\begin{array}{l}\text { R Of West } \\
\text { Bengal }\end{array}$ & -0.113 & $-0.289^{* *}$ & $0.153^{*}$ & 0.074 & $-0.256^{* *}$ & $0.178^{* *}$ \\
\hline $\begin{array}{l}\text { R Of } \\
\text { Jammu } \\
\text { \& Kashmir }\end{array}$ & -0.118 & 0.025 & $0.281^{* *}$ & $-0.308^{* *}$ & $-0.281^{* *}$ & $0.159^{*}$ \\
\hline
\end{tabular}


Table: 4 Shows correlation between parental bonding and different dimensions of aggression (experience and expression) of college students from West Bengal and Jammu \& Kashmir.

\begin{tabular}{|l|l|l|l|l|l|l|}
\hline & S-ANG & T-ANG & A-IN & A-OUT & A-CONT & A- EXP \\
\hline $\begin{array}{l}\text { MC Of West } \\
\text { Bengal }\end{array}$ & -0.088 & $0.133^{*}$ & 0.032 & $-0.256^{* *}$ & $-0.269^{* *}$ & 0.074 \\
\hline $\begin{array}{l}\text { MC Of } \\
\text { Jammu } \\
\text { \& Kashmir }\end{array}$ & 0.021 & 0.038 & 0.103 & -0.059 & 0.028 & 0.016 \\
\hline $\begin{array}{l}\text { MO Of West } \\
\text { Bengal }\end{array}$ & -0.018 & 0.026 & -0.015 & 0.088 & -0.053 & 0.061 \\
\hline $\begin{array}{l}\text { MO Of } \\
\text { Jammu } \\
\text { \& Kashmir }\end{array}$ & -0.086 & 0.005 & 0.063 & 0.010 & $-0.231^{* *}$ & $0.196^{* *}$ \\
\hline $\begin{array}{l}\text { FC Of West } \\
\text { Bengal }\end{array}$ & 0.038 & $0.279 * *$ & 0.009 & -0.046 & $-0.257^{* *}$ & $0.170^{*}$ \\
\hline $\begin{array}{l}\text { FC Of } \\
\text { Jammu } \\
\text { \& Kashmir }\end{array}$ & 0.047 & 0.064 & -0.031 & 0.070 & $0.154^{*}$ & 0.057 \\
\hline $\begin{array}{l}\text { FO Of West } \\
\text { Bengal }\end{array}$ & 0.92 & 0.106 & 0.065 & 0.017 & -0.119 & 0.121 \\
\hline $\begin{array}{l}\text { FO Of } \\
\text { Jammu } \\
\text { \& Kashmir }\end{array}$ & -0.055 & -0.047 & 0.008 & -0.100 & $-0.144^{*}$ & 0.039 \\
\hline
\end{tabular}

\section{DUSCUSSION}

One of the major objectives of the Present study was to investigate the relationship between aggression and its different correlates namely, personality, parental bonding, frustration, peer pressure and emotional intelligence, When it is considered in terms of two groups of students coming from two cultural set-up, i.e., from west Bengal and Jammu \& Kashmir.

Considering the personality dimensions, Agreeableness has been found to have negative relationship with anger control, when it is considered in terms of two groups of students coming from two cultural set-up, i.e., from west Bengal and Jammu \& Kashmir. The strongest Big 5 predictor of aggressive behaviour is Agreeableness, which is characterized as good-natured, trustful, and cooperative (John \& Srivastava, 1999). It is negatively related to aggressive behaviour (Gleason, Jensen- Campbell, \& Richardson, 2004) and violence (Heaven, 1996).

Neuroticism on the other hand, has been found to have relationship with trait anger, when it is considered in terms of groups of students coming from west Bengal and not from Jammu \& Kashmir. It is characterized by being easily upset and emotionally unstable (John \& Srivastava, 


\section{A Cross Cultural Study on Aggression in a Group of College Students from West Bengal and Jammu \& Kashmir}

1999) is positively related to aggressive behaviour (Sharpe \& Desai, 2001). Aggression does not role in a vacuum, some conditions certainly provoke aggression, but some are better at struggling or returning to provocation. Studies have revealed that greater aggressive response was seen under provocation for trait anger in individuals with high level neuroticism.

Extraversion have not however been found to have relationship to aggressive behaviour, when it is considered in terms of groups of students coming from west Bengal and not from Jammu \& Kashmir and is characterized as being talkative, assertive, and energetic (John \& Srivastava, 1999) and its relations with aggression are sometimes mixed.

Openness has been found to have positive correlation with anger in, when it is considered in terms of groups of students coming from Jammu \& Kashmir, but not in West Bengal. It is characterized by being, intellectual, logical, polished, and independent-minded (John \&Srivastava, 1999), tends to be unrelated to aggressive behaviour (e.g., Gleason et al., 2004). These individuals have the ability to hold in or suppress angry feelings and it has also been reflected from our finding in Jammu \& Kashmir only.

Conscientiousness has been found to have significant relationship with anger in, when it is considered in terms of two groups of students coming from two cultural set-up, i.e., from west Bengal and Jammu \& Kashmir. It is characterized by being responsible, orderly, and dependable (John \&Srivastava, 1999), and tends to be negatively related to aggression (Sharpe \& Desai, 2001). In the present study, the sample from Jammu \& Kashmir has also expressed significant negative relation with anger in.

Stress has been found to have a relationship with expression of anger, when it is considered in terms of two groups of students coming from two cultural set-up, i.e., from west Bengal and Jammu \& Kashmir. Persons with high level of stress are generally emotionally unstable and more poorly adjusted than others (Lazarus's 1966).

Considering the findings regarding the relationship between frustration and aggression, it is very much clearly found that different four subscales of frustration are significantly related with different dimensions of aggression both in case of West Bengal and Jammu \& Kashmir. There is considerable evidence supporting the view that frustration becomes a potent inducer of aggression when it is associated with personal attack, defeating, Inhibiting and preventing. In a number of investigations it has been shown that frustration produces hostility or aggression more readily when it is perceived as arbitrary, unjustified, intentional, or unmitigated rather than accidental or warranted (Dixit and Shrivastava 1987). The above statement has also been corroborated with the present result.

Parental bonding has been found to have a relationship with experience and expression of anger, when it is considered in terms of two groups of students coming from two cultural set-up, i.e., from west Bengal and Jammu \&Kashmir. Researches have revealed that maternal care and 


\section{A Cross Cultural Study on Aggression in a Group of College Students from West Bengal and Jammu \& Kashmir}

paternal care act as protective factors against the manifestation of hostile aggression. On the other hand, it can be said that those who perceive both their parents as overprotective has less capacity to control their angry tactics or approaches. Because overprotection can minimise the stress tolerance occasionally.

\section{STRENGTHS AND LIMITATIONS OF THE PRESENT STUDY}

In the present study both the experience and expression of anger has been studied from different perspectives like personality predisposition, as reaction of frustration, perceived life stress etc. Similarly, the influence of different external factors such as peer-pressure, parental bonding etc. have also been studied with reference to two cultural set-up, i.e., West Bengal and Jammu \& Kashmir. As aggression is becoming a pervasive psychosocial problem all over the world and different social/legal machineries have not yet been able to control its manifestations in different spheres of life, so from that standpoint the results obtained from the present study might give some new direction for identifying the proper correlates of their negative emotion which in turn may also help us to prevent its pathological expressions and may minimize the occurrence of violence and crime in the society.

The present study has certain limitations also which are-

As the experience and expression of anger has some close relation with different biological variables, so it would have been better if different biological correlates would also be incorporated with the present study for more global understanding of aggression.

Secondly, for a better generalization of the findings, the present sample size might not be considered as sufficient.

\section{REFERENCES}

Adams, D.W. (1966). The Family: A sociological Interpretation. Child Development, 6(2), 5663.

Andreu, J. Manuel, TakehiroFujihara, Takaya Kohyama, and J. Martin Ramirez. 1998. Justification of Interpersonal Aggression in Japanese, American, and Spanish Students. Aggressive Behavior 25: 185-195. 7 Dec. 2006.

Anderson, C. A., \& Bushman, B. J. (2002).Human aggression. Annual Review of Psychology, 53, 27-51.

Costa, P. T., \& McCrae, R. R. (1992). Revised NEO Personality Inventory (NEO-PI-R) and

NEO Five-Factor Inventory (NEO-FFI) professional manual. Odessa, FL: Psychological Assessment Resources.

Dixit, B.M. and Shrivastava, D.N. (1987): Reactions to Frustration Scale, Agra: National Psychological Corporation.

John, O. P., \&Srivastava, S. (1999). The Big-Five trait taxonomy: History, measurement, and theoretical perspectives. In L. Pervin \& O. P. John (Eds.), Handbook of personality: Theory and research (pp. 102-138). New York: Guilford Press.

Lazarus, R.S. (1966). Psychological stress and coping process. New York: McGraw-Hill. 


\section{A Cross Cultural Study on Aggression in a Group of College Students from West Bengal and Jammu \& Kashmir}

Nuttal, E. V. and Kalesnik, J. 1987. Personal violence in the schools: The role of the counselor. Journal of Counseling and Development, 65, 372-375.

Sharpe, J. P., \& Desai, S. (2001). The revised Neo Personality Inventory and the MMPI-2 Psychopathology Five in prediction of aggression. Personality and Individual Differences, 31, 505-518.

Ramirez, J.M., 1993, Acceptability of aggression in four Spanish regions and a comparison with other European countries. Aggressive Behaviour 19: 185-197.

Spielberger, C.D.(1998). Manual for the state trait anger expression Inventory.(STAXI).Odessa, FL., Psychological assessments Resources. 